ISSN: 2581-8341

Volume 04 Issue 10 October 2021

DOI: 10.47191/ijcsrr/V4-i10-16, Impact Factor: 5.825

IJCSRR@ 2021

www.ijesrr.org

\title{
Phase Wise Variation of Criteria Pollutants across India during COVID-19 Lockdown
}

\author{
Charu Tyagi ${ }^{1}$, Vijay Kumar Soni ${ }^{2}$, Ravi Ranjan Kumar ${ }^{3}$, Arpit Tiwari ${ }^{4}$ \\ ${ }^{1,3}$ Commission for Air Quality Management in NCR and Adjoining Areas \\ ${ }^{2,4}$ India Meteorological Department, New Delhi
}

\begin{abstract}
The COVID-19 epidemic forced many countries around the world to lockdown completely. This occlusion influenced the atmospheric composition positively due to reduced anthropogenic activities. Recently, many studies across India have shown how the COVID-19 lockdown has affected air quality in different cities. However, these studies did not examine the phased percentage variation in air pollutant concentrations across different states of India. In this study, percentage variation in the concentration of five criteria pollutant, $\mathrm{PM}_{10}, \mathrm{PM}_{2.5}, \mathrm{NO}_{2}, \mathrm{CO}$ and Ozone were studied for 13 states across India during four phases of COVID-19 lockdown. A significant decrease in air pollutant levels was observed in all four phases, with phase 1 and phase 2 reporting a maximum decrease. $\mathrm{PM}_{10}$ and $\mathrm{PM}_{2.5}, \mathrm{CO}$ and $\mathrm{NO}_{2}$ showed a decrease in concentration in all states. Ozone showed a mixed response, with both increase and decrease recorded across states. During the COVID-19 lockdown period in India, AOD levels were reduced by $10.25 \%$. This study will certainly help regulators set the guidelines and mitigation measures for appropriate control of air pollutants in different states in future.
\end{abstract}

KEYWORDS: Air Quality, COVID-19, India

\author{
ABBREVIATIONS: \\ AOD: Aerosol Optical Depth \\ CAAQMS: Continuous Ambient Air Quality Monitoring Station \\ CO: Carbon monoxide \\ COVID-19: Coronavirus Diseases 2019 \\ CPCB: Central Pollution Control Board \\ MODIS: Moderate Resolution Imaging Spectroradiometer \\ $\mathrm{NO}_{2}$ : Nitrogen dioxide \\ $\mathrm{O}_{3}$ : Ozone \\ $\mathrm{PM}_{10}$ : Particulate matter 10 \\ $\mathrm{PM}_{2.5}$ : Particulate matter 2.5
}

\section{INTRODUCTION}

The first case of COVID-19 in India was reported in Kerala on January 30, 2020. Given the growing number of COVID cases in India under the provisions of the Epidemiological Diseases Act of 1897, a temporary closure was announced. The first Janta curfew was announced on March 22, 2020. The full closure was then announced, which began on March 24, 2020 in four phases: Phase 1 (P1): March 25, 2020 - April 14, 2020 (21 days), Phase 2 (P2): April 15, 2020 - May 3rd, 2020 (19 days), Phase 3 (P3): May 4th, 2020 - May 17th, 2020 (14 days) and Phase 4(P4): May 18, 2020 - May 31, 2020 (14 days) to prevent the spread of COVID-19. The Indian government issued standards restricting human mobility, transportation, large gatherings, religious, academic, industrial and commercial establishments other than essential services. Gradual easing has also been introduced. In phase 3 and 4 of the lockdown, economic activity, public mobility and traffic were significantly relaxed. The phased variation in pollutants across the states must be examined in detail for determining the future policies and strategies accordingly.

Several studies have already been carried out over different locations in India, majority of them have reported considerable improvement in the air quality based on the analysis of different air pollutants from ground and satellite-based observations. Though most of them were carried out for the initial phases of lockdown over different cities and did not take into account the entire period 


\section{International Journal of Current Science Research and Review}

ISSN: 2581-8341

Volume 04 Issue 10 October 2021

DOI: 10.47191/ijesrr/V4-i10-16, Impact Factor: 5.825

IJCSRR@ 2021

www.ijesrr.org

and phase wise variation. This study on contrary takes into account the data from $1^{\text {st }}$ March-31 $31^{\text {st }}$ May 2020 and also the analysis has been done for all four phases over 13 states of India based on the data obtained from Continuous Ambient Air Quality Monitoring Stations (CAAQMS) of CPCB (Central Pollution control Board). Singh et al. (2020) carried out the pollutant analysis between $25^{\text {th }}$ March- $3^{\text {rd }}$ May2020 using CPCB data for 134 locations over different geographical locations of India and reported significant reduction in $\mathrm{PM}_{2.5}, \mathrm{PM}_{10}, \mathrm{NO}_{2}$, and $\mathrm{CO}$. They also reported mixed variation over different regions for $\mathrm{SO}_{2}$ and $\mathrm{O}_{3}$. Shehzad et al. (2020) reported the reduction in $\mathrm{NO}_{2}$ over Mumbai and Delhi during January-April 2020 as compared to the same period over 2019 based on Sentinel-5P and ground data from CPCB. Biswal et al. (2020) also examined the impact of lockdown over $\mathrm{NO}_{2}$ (tropospheric) over India and the study showed the reduction over different Phases as $12.7 \%$ reduction in Phase $1,13.7 \%$ reduction in Phase 2, 15.9\% reduction in Phase 3 and 6.1\% reduction over Phase 4. Mahato et al. (2020) reported the air quality improvement over NCT Delhi between $3^{\text {rd }}$ March-14 $4^{\text {th }}$ April, 2020 and reported maximum reduction in Particulate matter (>50\%). Bera et al. (2020) studied pollutants like $\mathrm{PM}_{10}, \mathrm{PM}_{2.5}, \mathrm{NO}_{2}$ and $\mathrm{CO}$ over Kolkata during lockdown phase (March-May) in comparison with previous years (2017-2019) and reported significant reduction along the sustainable management measures that can be adopted in Kolkata for further management. Singh et al. (2020) reported decline in AQI, $\mathrm{PM}_{2.5}$ and $\mathrm{NO}_{2}$ over five major cities Mumbai, Delhi, Hyderabad, Chennai and Kolkata during lockdown period in 2020 compared to 2019. Mor et al. (2020) studied 14 air pollutants in categories particulate matter, trace gases and VOC's over initial three phases of lockdown over Chandigarh. The results reported a significant reduction during first and second lockdown phases and increase in the level of few pollutants over third phase. The study also revealed Vehicular pollution as the primary source of pollution.

Human mobility is closely related to air pollution. To understand this mechanism, human mobility data for walking and driving was collected from covid19.apple.com/mobility. While these data do not take into account the total mobility of vehicles and people during this period, they do provide insight into the trend towards better understanding of their effects on air pollutant concentrations. It is clear from the data for 6 major cities in India (Bangalore, Chennai, Delhi, Hyderabad, Mumbai and Pune) that mobility in terms of driving and walking decreases drastically from late March to May 2020 (Fig.1). The phase wise analysis of COVID-19 lockdown (Fig. 2) showed the increased mobility in phase 3 and phase 4 due to the ease of the restrictions which clearly affect the concentrations of atmospheric constituents.

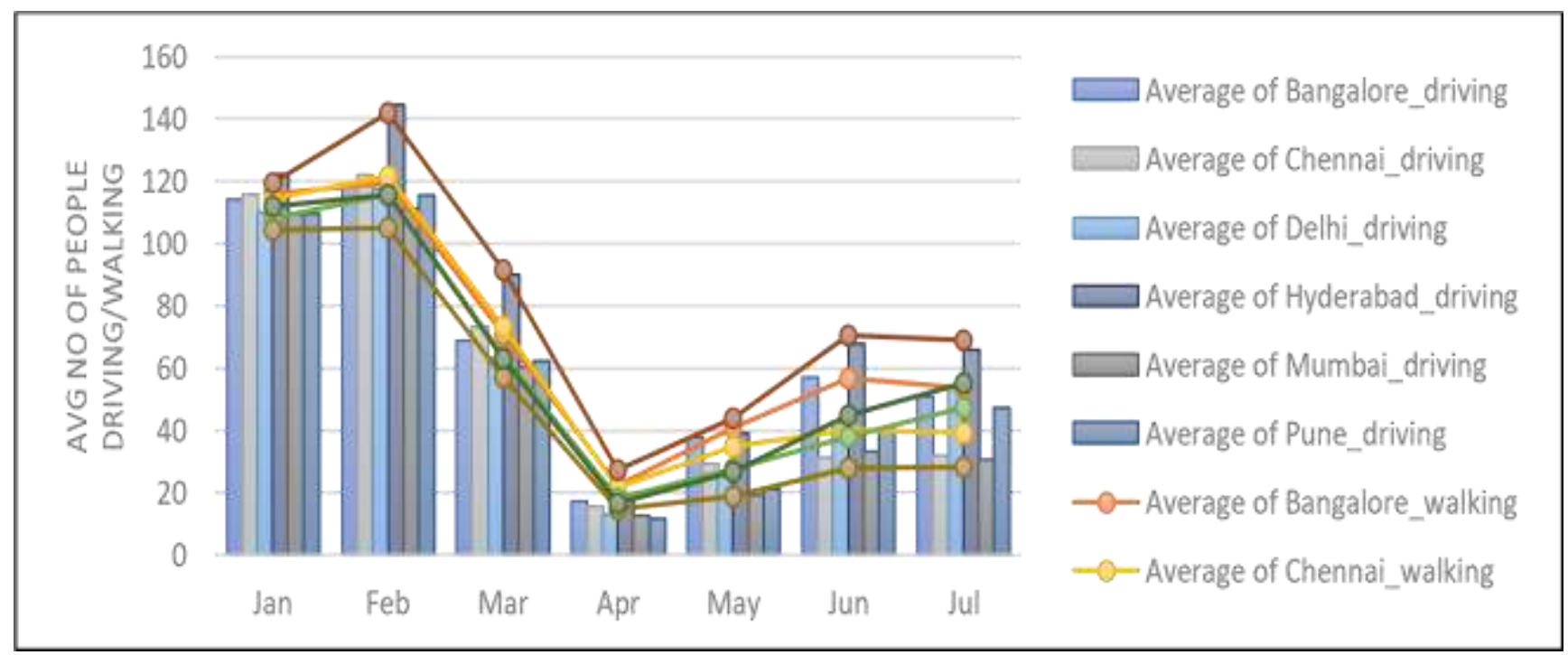

Fig.1. Human Mobility trend between January to July, 2020 


\section{International Journal of Current Science Research and Review}

ISSN: 2581-8341

Volume 04 Issue 10 October 2021

DOI: 10.47191/ijesrr/V4-i10-16, Impact Factor: 5.825

IJCSRR@ 2021

www.ijesrr.org

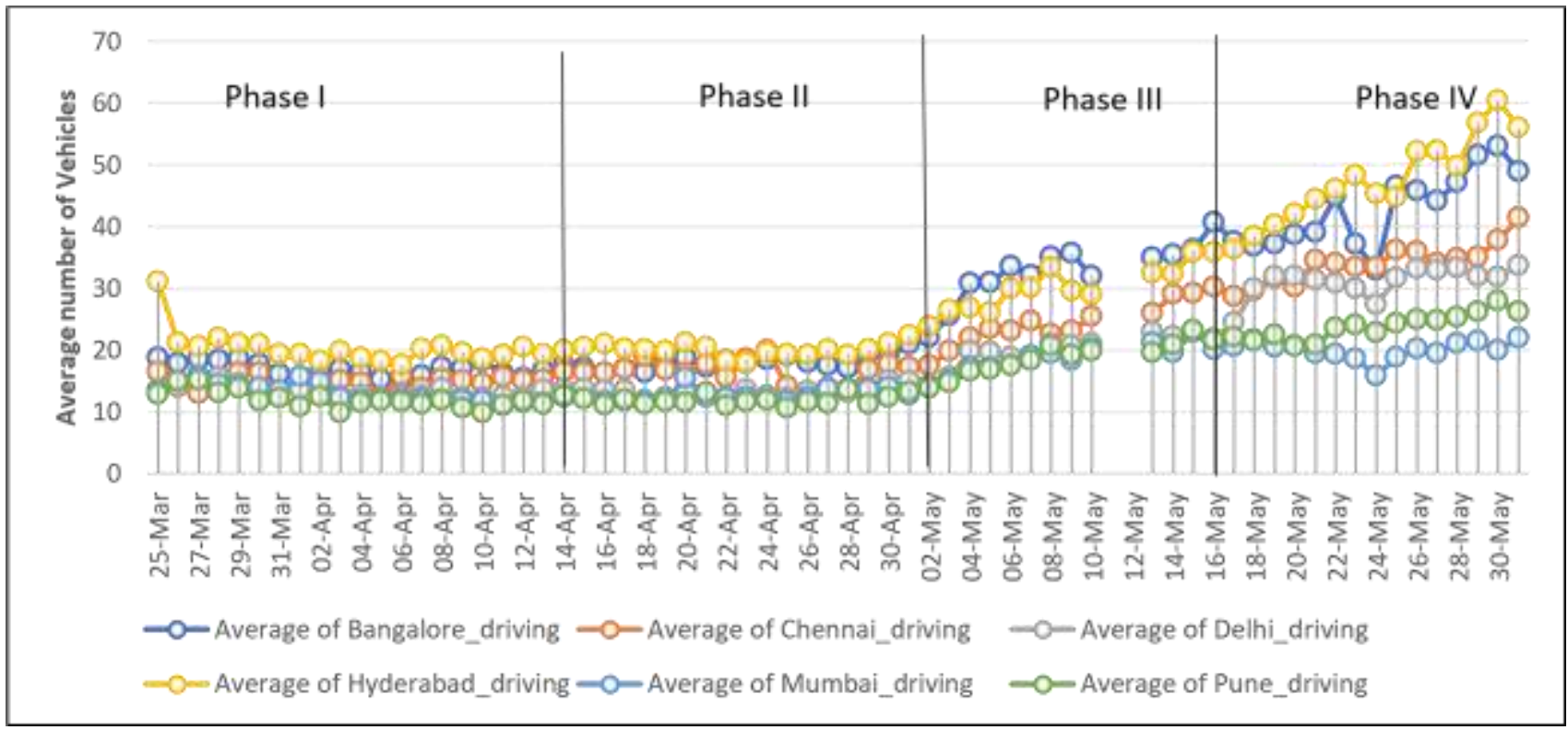

Fig. 2. Vehicular mobility between January to July, 2020

It is important to note that, despite the positive environmental impact, this closure also had a negative impact on the socio-economic part. The results of this study will surely help policymakers understand the background levels of pollutants in different states during four phases of COVID-19 lockdown and determine the strategy accordingly to reduce the threat of air pollution.

\section{MATERIALS AND METHODS}

In the present study, comprehensive air quality data from 202 stations for 13 states across India were used. The data was collected from CAAQMS, CPCB, via https://app.cpcbccr.com/ccr/\#/ caaqm-dashboard-all / caaqm-Landing. States with at least 5 monitoring stations were considered for the study. In this work the phased variation of pollutants over Andhra Pradesh (AP), Delhi (DL), Gujarat (GJ), Haryana (HR), Karnataka (KR), Kerala (KL), Madhya Pradesh (MP), Maharashtra (MH) examined, Punjab (PB), Rajasthan (RJ), Telangana (TS), Uttar Pradesh (UP) and West Bengal (WB) were examined in comparison to the same period in 2019. The air quality pollutants analyzed in this study are $\mathrm{PM}_{10}, \mathrm{PM}_{2.5}, \mathrm{NO}_{2}, \mathrm{CO}$ and $\mathrm{O}_{3}$. While studying the air pollutants over the same time period is for different years, the similarity of meteorology is an important condition. The similarity in meteorology during the lockdown period in 2020 and the same period in 2019 was confirmed by a recent study by Singh et al. (2020) over India by The main objective of this study is to analyze the percentage change in the concentration of pollutants like $\mathrm{PM}_{10}, \mathrm{PM}_{2.5}, \mathrm{NO}_{2}, \mathrm{CO}$ and $\mathrm{O}_{3}$ during different phases of COVID-19 lockdown (March 1 to May 31, 2020) compared to the same period over 2019. Hourly mass concentrations of these pollutants in the area were downloaded from the CAAQMS website (CPCB 2020). The hourly data for $\mathrm{PM}_{10}, \mathrm{PM}_{2.5}, \mathrm{NO}_{2}, \mathrm{CO}$ and $\mathrm{O}_{3}$ were averaged daily for all locations, which are then averaged for obtaining the concentrations across different states. The data quality was ensured by filtering and taking out outliers, constant and missing values. Only locations with valid data were considered for the analysis. The descriptive statistics, percentage change was calculated using Microsoft Excel and phase wise data was plotted with the help of R Studio. The satellite data for Aerosol optical depth (AOD) at $550 \mathrm{~nm}$ over India has been taken from MODIS (Moderate Resolution Imaging Spectroradiometer) on board Terra and Satellite for 2019 and 2020 from $25^{\text {th }}$ March-31 ${ }^{\text {st }}$ May to analyse the impact of lockdown on aerosol concentration.

The total percentage change $(\mathrm{Pc})$ in the pollutant concentrations over the lockdown phases was calculated according to the following formula

$$
P_{C}=\left(\frac{P_{l}-P_{p}}{P_{P}}\right) * 100
$$

Where, $\mathrm{P}_{\mathrm{c}}$ is the percentage change, $P_{l}$ is the average concentration of a pollutant in the current year during the lockdown period, $\mathrm{Pp}$ is the average concentration of a pollutant in the previous year during the same period. 


\section{International Journal of Current Science Research and Review}

ISSN: 2581-8341

Volume 04 Issue 10 October 2021

DOI: 10.47191/ijcsrr/V4-i10-16, Impact Factor: 5.825

IJCSRR@ 2021

www.ijesrr.org

\section{RESULTS}

\section{PM10 and PM2.5}

During the COVID-19 lockdown in 2020, a significant decrease in particulate levels was observed in India compared to the same period in 2019. The phased variation of $\mathrm{PM}_{10}$ and $\mathrm{PM}_{2.5}$ in different states is shown in Fig. 3 and 4 respectively. In 2020, $\mathrm{PM}_{10}$ and $\mathrm{PM}_{2.5}$ decreased significantly in all states compared to 2019. Lower human activities such as vehicles, industry, construction, and open burning have certainly resulted in particulate reductions in all states. From March to May 2020, overall $\mathrm{PM}_{10}$ reductions ranged from $22.08 \%$ in Kerela to $45.43 \%$ in Uttar Pradesh compared to the same period in 2019. Most states saw a reduction in PM 10 of more than $30 \%$. $\mathrm{PM}_{2.5}$ concentration also showed a decrease in all states, with a maximum reduction in $\mathrm{PM}_{2.5}$ levels observed over Karnataka (41.94\%). The percentage change in particle concentrations in different phases of the closure showed a minimal decrease in phase 4 due to an increase in anthropogenic activities due to the lifting of major transport restrictions, the opening of industries and offices. A maximum reduction in $\mathrm{PM}_{10}$ over DL (-63.36\%), HR (-58.89\%), MP (-45.08\%), PB (-65.99\%), RJ (-57.30\%) and UP (-62.25\%) was observed in phase 1 of the COVID-19 lockdown, with the maximum reduction in phase II recorded in GJ ($48.88 \%), \mathrm{KR}(44.69 \%), \mathrm{MH}(-45.70 \%)$ and WB (-57.34\%) and maximum reduction in phase III was observed over AP (-64.55\%), KL $(-37.02 \%)$ and TS (-49.26\%). Most states showed a maximum reduction in $\mathrm{PM}_{2.5}$ in phase I such as DL (-54.75\%), HR ($55.09 \%)$, KL (-23.90\%), MP (-32.44\%), PB (-60.40\%), RJ (-55.62\%) and UP (-55.79\%). States like GJ (-53.35\%) and KR (-49.91\%) showed a maximum reduction in phase 2 and AP $(-64.86 \%)$, TS $(-32.69 \%)$ and WB $(-58,50 \%)$ showed a maximum reduction in P3. Maharashtra only showed maximum reduction in phase $4(48.79 \%)$ due to severe restrictions during this phase. The phased reduction in all pollutants in different states is shown in Table 1.

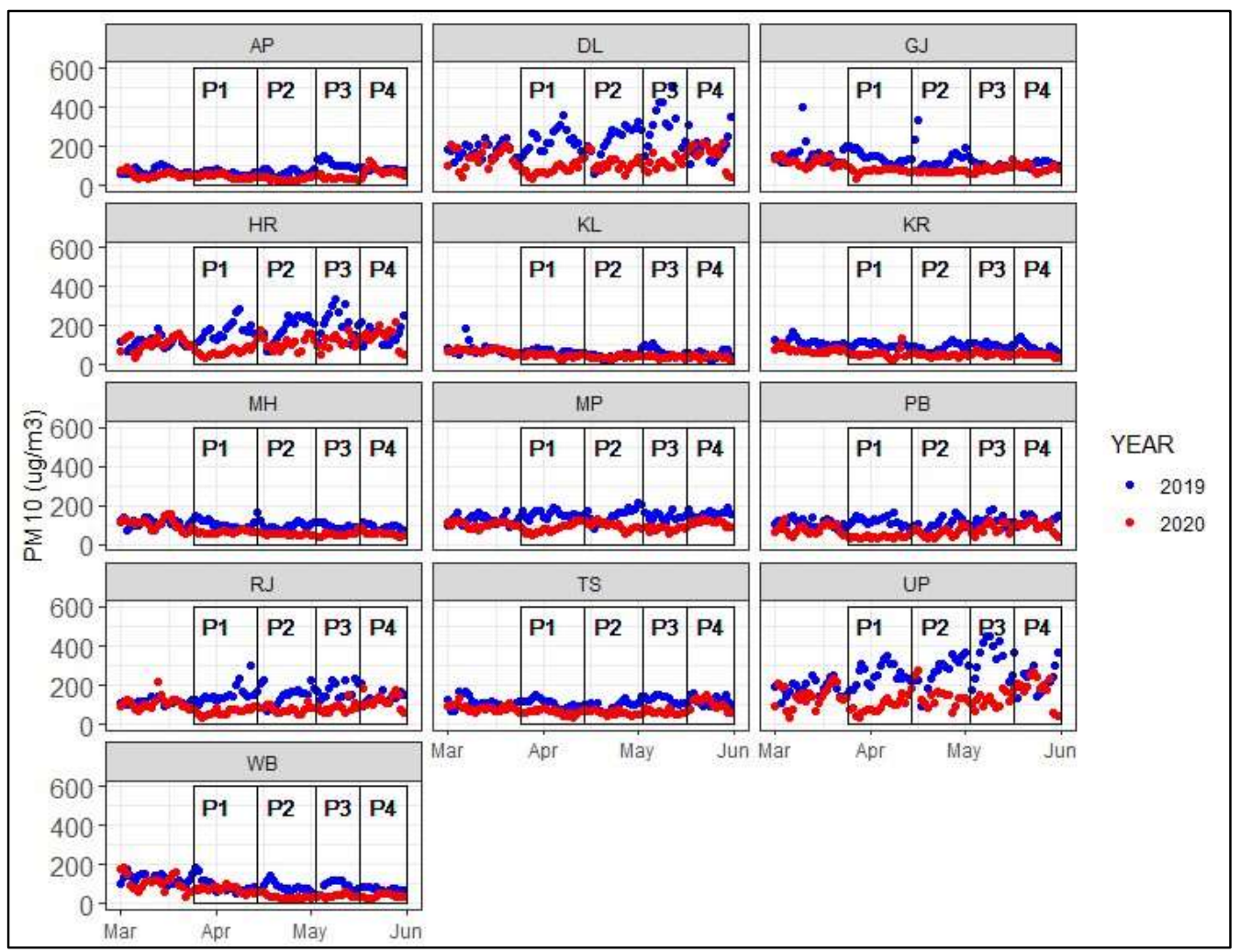

Fig.3. Variation of $\mathrm{PM}_{10}$ over different phases of COVID-19 lockdown 


\section{International Journal of Current Science Research and Review}

ISSN: 2581-8341

Volume 04 Issue 10 October 2021

DOI: 10.47191/ijcsrr/V4-i10-16, Impact Factor: 5.825

IJCSRR@ 2021

www.ijesrr.org

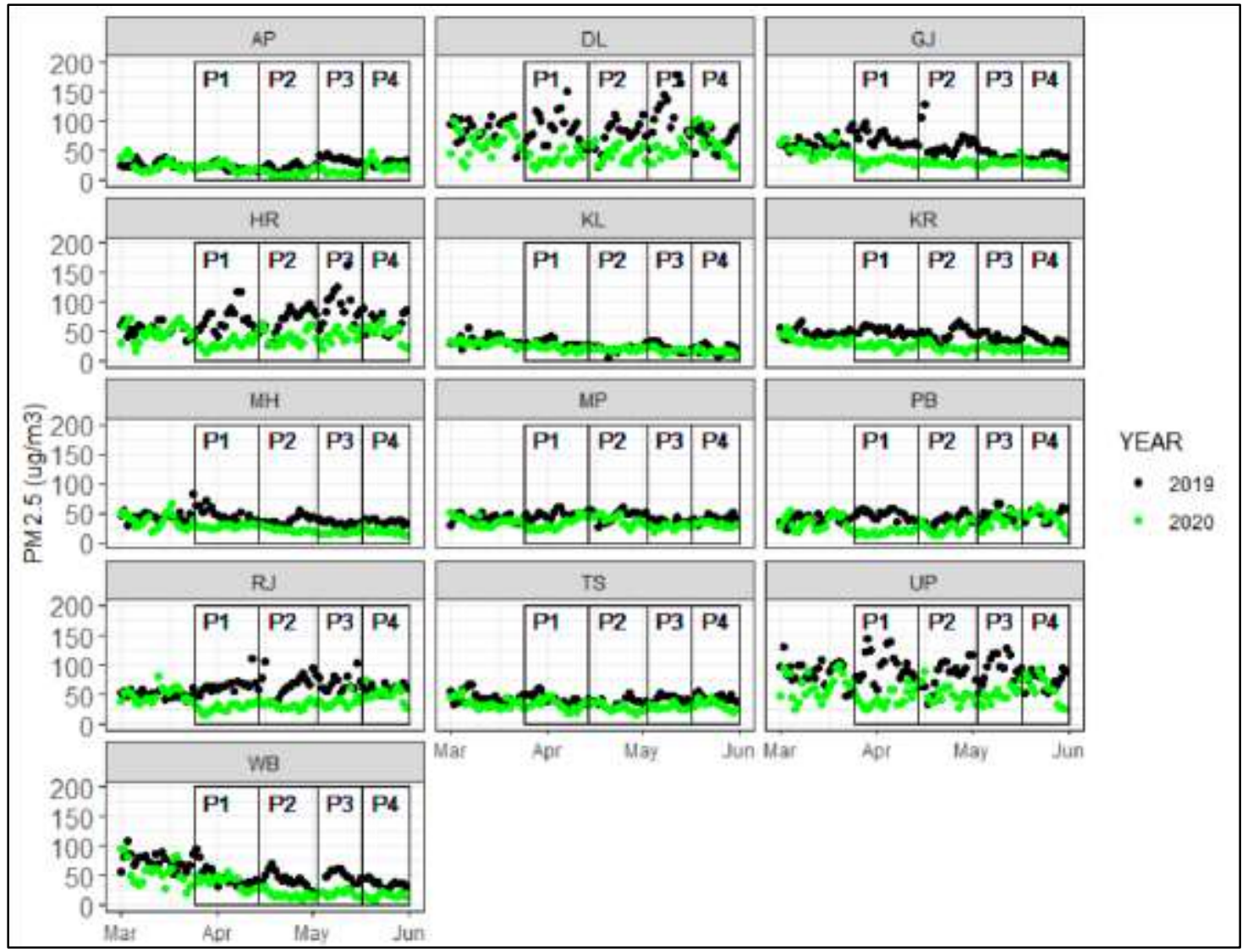

Fig.4. Variation of $\mathrm{PM}_{2.5}$ over different phases of COVID-19 lockdown

\section{CO}

$\mathrm{CO}$ comes mainly from automobile sources and combustion processes. It stays in the atmosphere for a long time and travels long distances. The limited flow of vehicles and anthropogenic activities have led to a decrease in CO levels in all states. In phase 1 and phase 3, a maximum reduction in $\mathrm{CO}$ was observed in most states. In phase 1 there was a maximum reduction over AP (-33.75\%), DL (-49.72\%), GJ (-60.13\%), HR (-30.31\%) and RJ (-36.21\%) and in phase 3 over KL ( $-40.28 \%)$, PB (-45.70\%), TS (-33.29\%), UP (-11.92\%) and WB (-40.63\%). MP (33.0\%) and MH (-46.04\%) showed a maximum reduction in phase 4 and KR (-37.27\%) only in phase 2 . The influence of lockdown on the reduction in CO concentration over Uttar Pradesh (UP) was not significant, as a slight increase of $9.98 \%$ and $2.49 \%$ was observed in phase 2 and phase 4 . In Phase 4 , an $8.42 \%$ increase over KL and $1.21 \%$ increase over AP were also observed. An increase in the CO concentration in phase 4 in KL, UP and AP could be the result of relaxed norms on the movement of vehicles and operation of industries during this phase. It is observed that the average CO concentration in both 2019 and 2020 during this period is within the prescribed limit of $4 \mathrm{mg} / \mathrm{m}^{3}$ (Fig. 5) according to the NAAQS (National Ambient Air Quality Standard) standards prescribed by CPCB. 


\section{International Journal of Current Science Research and Review}

ISSN: 2581-8341

Volume 04 Issue 10 October 2021

DOI: 10.47191/ijesrr/V4-i10-16, Impact Factor: 5.825

IJCSRR @ 2021

www.ijesrr.org

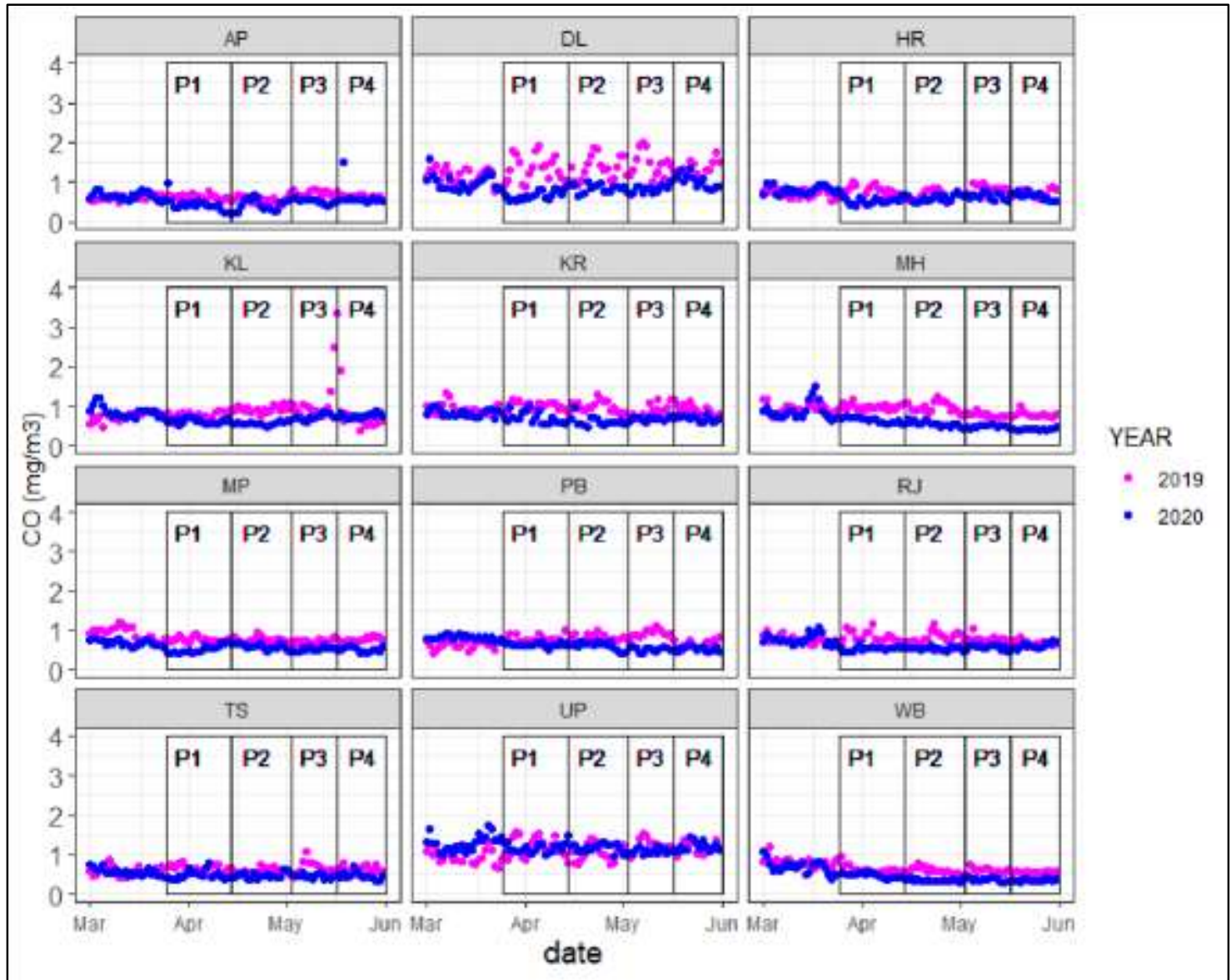

Fig.5. Variation of CO over different phases of COVID-19 lockdown

\section{Ozone}

Ozone showed a mixed response compared to other pollutants. During the lockdown months in 2020, both an increase and a decrease were observed between states compared to the 2019 period. Most states showed concentration reductions greater than $20 \%$, with maximum reductions observed against Kerala (57.29\%) and Maharashtra (36.10\%). Delhi and states such as Gujarat, Madhya Pradesh, Punjab, Rajasthan, and West Bengal showed increases in total concentrations, although the total increase for most of them, with the exception of West Bengal (32.76\%), was less than 10\%. The rise in ozone levels is due to the higher temperatures in these states in late April and May. According to the phased analysis, 5 states (KR, KL, MH, TS and UP) showed a reduction across all phases of the COVID-19 lockdown in relation to 2019 with a maximum reduction of KR (-35.06\%) and KL (-60.05\%) over phase 4 and $\mathrm{MH}(-43.31 \%)$, TS $(40.62 \%)$ and UP $(-28.85 \%)$ over phase 2. States like PB and WB showed an increase in the $\mathrm{O}_{3}$ concentration across all phases, while states like DL, GJ, HR, MP, RJ, and AP showed a mixed increase and decrease response reported across different phases (shown in Table 1 and Fig.6). 
ISSN: 2581-8341

Volume 04 Issue 10 October 2021

DOI: 10.47191/ijesrr/V4-i10-16, Impact Factor: 5.825

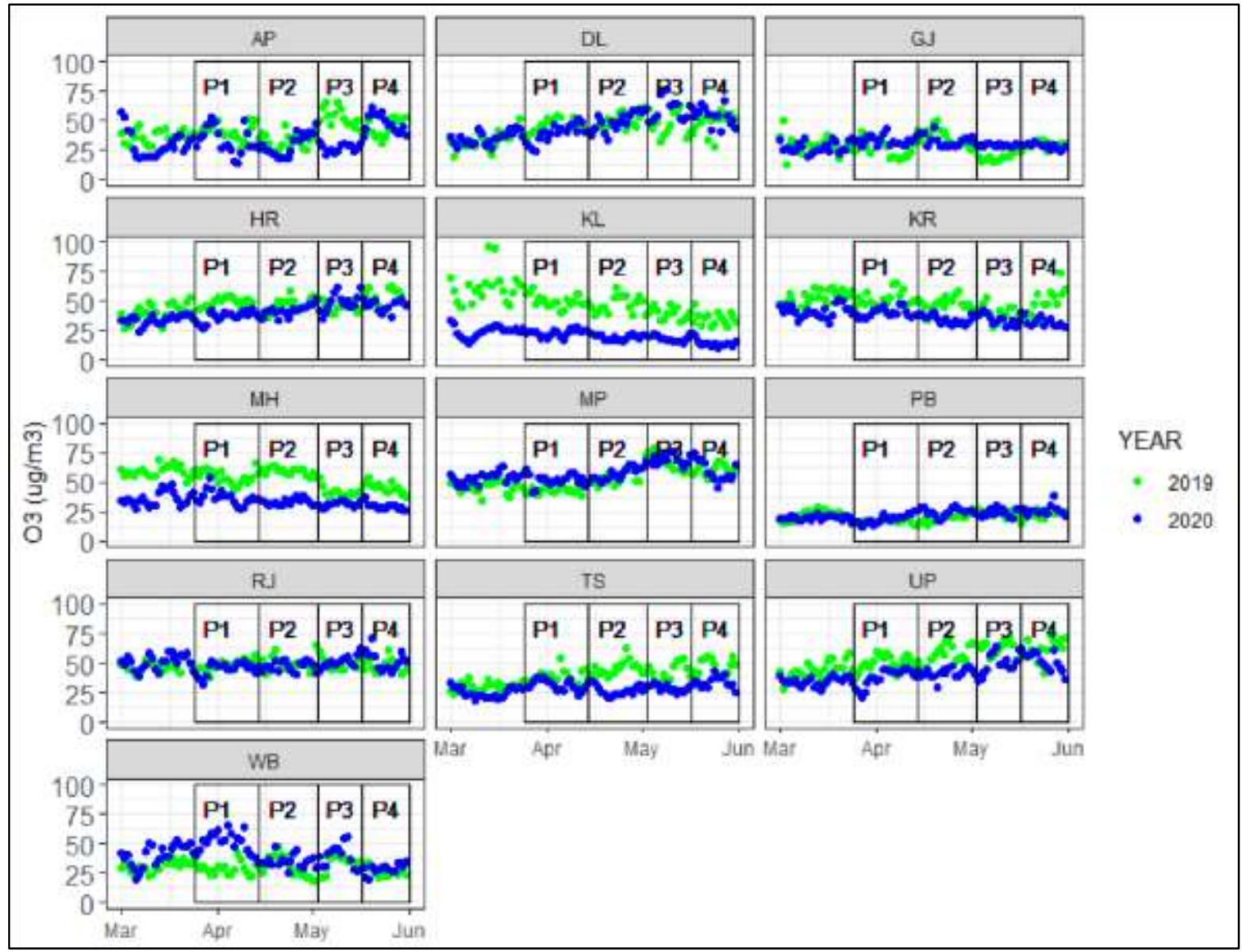

Fig.6. Variation of $\mathrm{O}_{3}$ over different phases of COVID-19 lockdown

$\mathrm{NO}_{2}$

Nitrogen dioxide $\left(\mathrm{NO}_{2}\right)$ is a type of nitrogen oxide (NOx) that is released into the atmosphere primarily through combustion processes. Nitrogen oxides (NO) in combination with oxygen create $\mathrm{NO}_{2}$ in the atmosphere. $\mathrm{NO}_{2}$ comes mainly from local sources and stays in the atmosphere for a shorter period of time. $\mathrm{NO}_{2}$ is responsible for acid rain in some areas and also helps with the formation of secondary pollutants $\left(\mathrm{PM}\right.$ and $\left.\mathrm{O}_{3}\right)$. In India, a decrease in atmospheric $\mathrm{NO}_{2}$ concentration was observed between $\mathrm{March}$ and May 2020 compared to the same period in 2019, although this decrease is not uniform across countries. Delhi, Gujarat, Karnataka and Punjab showed a decrease of more than $40 \%$ during the lockdown months, while in Madhya Pradesh and Maharashtra the decrease was not significant. Fig 7 shows the phase-wise variation of $\mathrm{NO}_{2}$ during COVID-19 over different states. According to the results, a decrease was observed in all four phases in all states, with the exception of phase 4 in MP, which saw a slight increase of $6.25 \%$ during phase 4 , which is the result of enabling anthropogenic activities in that phase. In most states, a maximum reduction was observed in phase 1 , such as HR $(-48.86 \%)$, KR (-64.0\%), PB (-59.05\%), RJ (-59.38\%), TS (-46.42\%) and UP (-58.84\%). DL $(-59.56 \%)$, MH $(66.49 \%)$ and WB $(-56.88 \%)$ showed a maximum reduction in phase 2 and GJ $(-73.18 \%)$ in phase 4 and AP ($60.80 \%$ ) in phase 3 . 
International Journal of Current Science Research and Review

ISSN: 2581-8341

Volume 04 Issue 10 October 2021

DOI: 10.47191/ijesrr/V4-i10-16, Impact Factor: 5.825

IJCSRR@ 2021

www.ijjcsrr.org

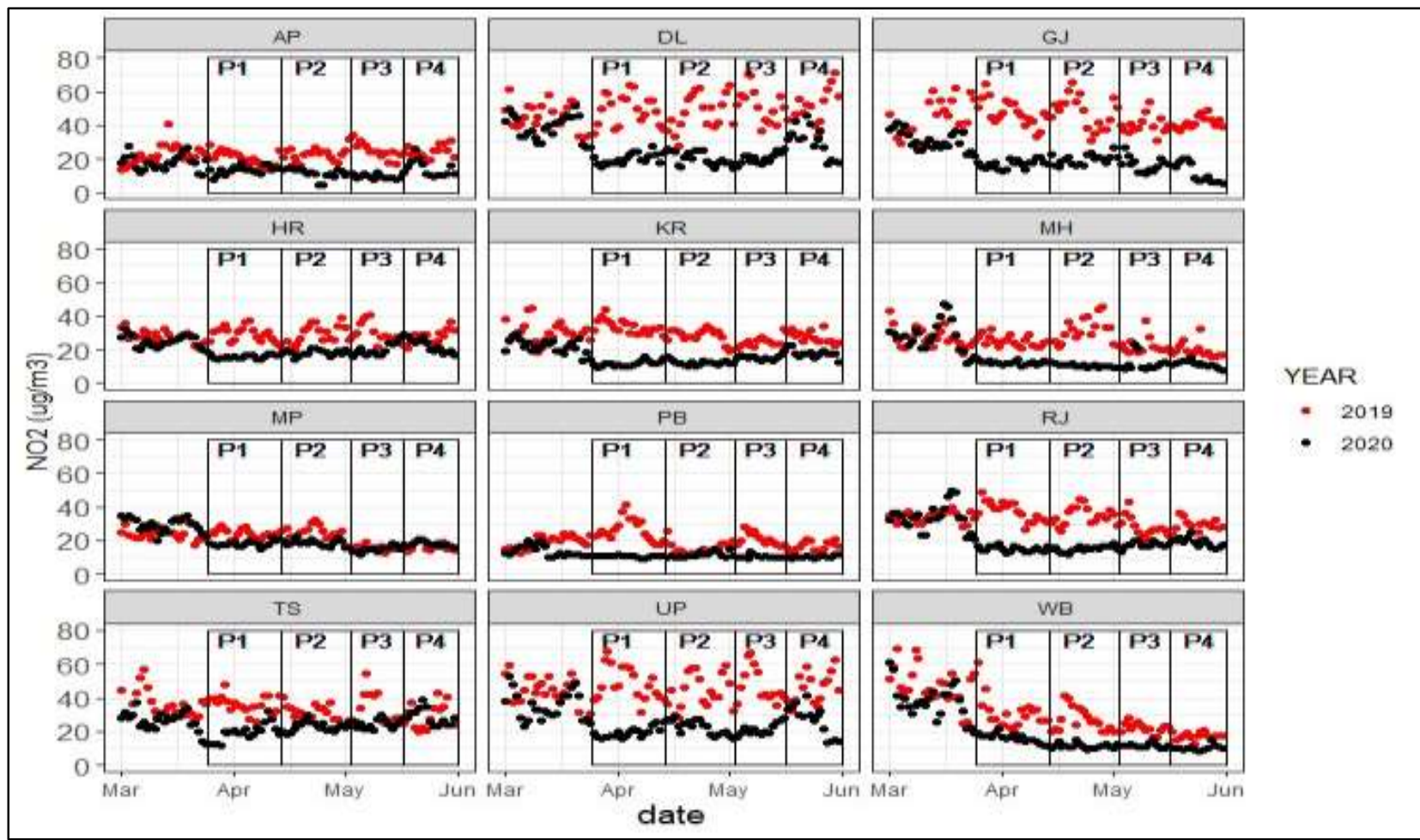

Fig.7. Variation of $\mathrm{NO}_{2}$ over different phases of COVID-19 lockdown

Table 1: Percentage change in the pollutant concentration over different phases of COVID-19 lockdown

\begin{tabular}{|c|c|c|c|c|c|c|c|c|c|c|c|c|c|c|c|c|c|c|c|c|}
\hline \multirow[b]{2}{*}{ State } & \multirow[b]{2}{*}{ P1 } & \multicolumn{3}{|c|}{ PM10 } & \multicolumn{5}{|c|}{ PM2.5 } & \multicolumn{3}{|c|}{ NO2 } & \multicolumn{5}{|c|}{ CO } & \multicolumn{3}{|c|}{ Ozone } \\
\hline & & P2 & P3 & P4 & P1 & P2 & P3 & P4 & P1 & P2 & P3 & P4 & P1 & P2 & P3 & P4 & P1 & P2 & P3 & P4 \\
\hline AP & -26.64 & -48.32 & -64.55 & -8.15 & -3.31 & -42.91 & -64.86 & -14.23 & -32.82 & -50.69 & -60.80 & -41.49 & -33.75 & -23.01 & -29.22 & 1.21 & -20.24 & -11.66 & -48.08 & 6.90 \\
\hline $\mathrm{DL}$ & -63.36 & -51.17 & -57.94 & -17.68 & -54.75 & -41.19 & -48.56 & -16.27 & -58.37 & -59.56 & -58.52 & -40.68 & -49.72 & -38.89 & $-41.33-2$ & 23.49 & -13.21 & -0.13 & 31.88 & 9.15 \\
\hline GJ & -46.72 & -48.88 & -10.15 & -19.20 & -52.77 & -53.35 & -20.25 & -32.00 & -63.73 & -59.55 & -58.97 & -73.18 & -60.13 & -54.49 & $-16.80-7$ & 75.73 & 23.80 & -6.54 & 52.22 & -5.50 \\
\hline HR & -58.89 & -39.53 & -46.82 & -6.63 & -55.09 & -40.66 & -53.03 & -23.22 & -44.86 & -38.01 & -30.20 & -20.63 & -30.31 & -12.06 & $-21.53-1$ & 12.79 & -21.44 & -10.99 & 10.25 & -13.50 \\
\hline KR & -44.15 & -44.69 & -40.16 & -40.10 & -48.49 & -49.91 & -45.01 & -49.37 & -64.00 & -55.81 & -36.84 & -36.47 & -30.70 & -37.27 & $-25.43-2$ & 22.24 & -21.50 & -26.94 & -13.30 & -35.06 \\
\hline KL & -28.92 & -21.11 & -37.02 & -27.29 & -23.90 & -8.38 & -14.82 & -18.09 & NA & NA & NA & NA & -20.95 & -38.98 & -40.28 & 8.42 & -53.84 & -58.73 & -52.86 & -60.05 \\
\hline MP & -45.08 & -36.41 & -44.84 & -25.72 & -32.44 & -17.19 & -27.43 & -23.97 & -24.75 & -23.53 & -3.47 & 6.25 & -31.74 & -21.93 & $-28.81-3$ & 33.00 & 18.81 & 4.36 & 3.71 & -3.68 \\
\hline $\mathrm{MH}$ & 40.27 & -45.70 & -37.60 & -40.28 & -39.80 & -43.84 & -44.62 & -48.79 & -51.81 & -66.49 & -44.86 & -42.55 & -35.52 & -43.95 & $-36.46-4$ & 46.04 & -32.11 & -43.31 & -23.03 & -35.31 \\
\hline PB & -65.99 & -40.18 & -32.56 & -21.78 & -60.40 & -34.94 & -21.65 & -8.55 & -59.05 & -21.73 & -49.84 & -37.17 & -17.20 & -24.67 & $-45.70-1$ & 16.83 & 13.81 & 18.54 & 5.63 & 11.85 \\
\hline RJ & -57.30 & -49.54 & -51.64 & -8.33 & -55.62 & -51.74 & -44.12 & -14.46 & -59.38 & -56.79 & -35.84 & -35.91 & -36.21 & -35.50 & $-25.39-1$ & 10.77 & -5.29 & -6.68 & 8.52 & 9.46 \\
\hline TS & -40.47 & -39.37 & -49.26 & -16.11 & -22.61 & -22.67 & -32.69 & -28.15 & -46.42 & -22.07 & -26.62 & -4.30 & -25.76 & -17.13 & $-33.29-2$ & 26.25 & -17.32 & -40.62 & -31.20 & -27.54 \\
\hline UP & -62.25 & -47.08 & -62.19 & -22.57 & -55.79 & -39.94 & -47.46 & -21.47 & -58.84 & -50.43 & -52.90 & -43.63 & -6.10 & 9.98 & -11.92 & 2.49 & -24.54 & -28.85 & -15.96 & -18.36 \\
\hline WB & -20.28 & -57.34 & -55.56 & -46.99 & -19.36 & -57.14 & -58.50 & -55.73 & -47.53 & -56.88 & -48.23 & -41.62 & -23.33 & -39.35 & $-40.63-3$ & 36.82 & 76.85 & 17.99 & 14.20 & 11.23 \\
\hline
\end{tabular}


International Journal of Current Science Research and Review

ISSN: 2581-8341

Volume 04 Issue 10 October 2021

DOI: 10.47191/ijcsrr/V4-i10-16, Impact Factor: 5.825

Table 2: Average pollutant concentration across different states between March-May in 2019 and 2020

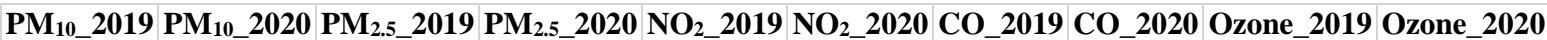

\begin{tabular}{|c|c|c|c|c|c|c|c|c|c|c|c|}
\hline \multirow{2}{*}{ AP } & Avg & 76.50 & 49.87 & 26.72 & 20.07 & 22.57 & 17.90 & 0.62 & 0.61 & 40.44 & 31.13 \\
\hline & SD & 26.81 & 22.12 & 9.29 & 10.20 & 8.23 & 9.23 & 0.24 & 0.23 & 16.72 & 18.48 \\
\hline \multirow{2}{*}{ DL } & Avg & 219.38 & 122.51 & 84.01 & 52.41 & 48.54 & 26.62 & 1.30 & 0.86 & 43.93 & 45.69 \\
\hline & SD & 95.50 & 62.93 & 42.82 & 30.55 & 20.11 & 13.27 & 0.59 & 0.31 & 33.64 & 25.62 \\
\hline \multirow{2}{*}{ GJ } & Avg & 133.55 & 90.58 & 57.34 & 36.12 & 44.24 & 20.16 & 3.55 & 1.48 & 28.44 & 30.32 \\
\hline & SD & 54.36 & 32.39 & 24.23 & 14.90 & 16.68 & 11.37 & 3.06 & 0.67 & 22.65 & 22.05 \\
\hline \multirow{2}{*}{ HR } & Avg & 165.96 & 108.98 & 68.91 & 43.29 & 28.64 & 20.42 & 0.74 & 0.65 & 46.49 & 40.94 \\
\hline & SD & 70.14 & 47.08 & 26.44 & 17.45 & 10.16 & 6.43 & 0.23 & 0.19 & 23.07 & 16.96 \\
\hline \multirow{2}{*}{ KL } & Avg & 65.46 & 51.01 & 23.57 & 27.79 & NA & NA & 0.86 & 0.71 & 48.71 & 20.81 \\
\hline & SD & 25.51 & 17.98 & 7.79 & 10.83 & NA & NA & 0.44 & 0.17 & 19.34 & 8.99 \\
\hline \multirow{2}{*}{ KR } & Avg & 99.02 & 59.85 & 45.64 & 26.50 & 29.24 & 16.07 & 0.94 & 0.71 & 49.06 & 37.39 \\
\hline & SD & 32.65 & 21.97 & 15.87 & 10.64 & 11.44 & 6.86 & 0.35 & 0.21 & 24.01 & 13.09 \\
\hline \multirow{2}{*}{ MP } & Avg & 146.04 & 96.26 & 33.67 & 43.18 & 21.72 & 20.61 & 0.80 & 0.58 & 53.07 & 57.34 \\
\hline & SD & 42.59 & 28.80 & 12.39 & 15.48 & 9.60 & 8.29 & 0.22 & 0.18 & 22.83 & 20.92 \\
\hline \multirow{2}{*}{ MH } & Avg & 101.85 & 70.40 & 26.40 & 41.36 & 25.69 & 15.71 & 0.90 & 0.62 & 53.25 & 34.03 \\
\hline & SD & 26.85 & 29.66 & 11.77 & 12.88 & 11.93 & 9.88 & 0.27 & 0.23 & 14.09 & 12.72 \\
\hline \multirow{2}{*}{ PB } & Avg & 114.63 & 70.00 & 30.90 & 43.97 & 19.77 & 11.68 & 0.75 & 0.64 & 20.92 & 22.31 \\
\hline & SD & 41.46 & 34.74 & 15.83 & 13.87 & 7.77 & 3.19 & 0.29 & 0.16 & 9.12 & 9.70 \\
\hline \multirow{2}{*}{ RJ } & Avg & 143.21 & 90.61 & 39.62 & 61.26 & 33.31 & 20.91 & 0.78 & 0.61 & 48.19 & 49.17 \\
\hline & SD & 60.36 & 39.50 & 16.03 & 21.99 & 11.48 & 10.58 & 0.33 & 0.21 & 22.47 & 21.49 \\
\hline \multirow{2}{*}{ TS } & Avg & 110.15 & 73.68 & 31.92 & 42.34 & 33.40 & 24.13 & 0.62 & 0.49 & 39.31 & 28.71 \\
\hline & SD & 34.83 & 28.78 & 10.58 & 12.70 & 14.85 & 7.65 & 0.27 & 0.18 & 19.89 & 11.34 \\
\hline \multirow{2}{*}{$\mathbf{U P}$} & Avg & 246.18 & 134.34 & 53.84 & 88.11 & 45.83 & 25.60 & 1.10 & 1.19 & 53.83 & 41.71 \\
\hline & SD & 105.86 & 70.45 & 27.55 & 37.22 & 19.52 & 12.03 & 0.46 & 0.37 & 30.73 & 19.87 \\
\hline \multirow{2}{*}{ WB } & Avg & 96.87 & 64.42 & 32.43 & 51.96 & 30.67 & 19.03 & 0.65 & 0.47 & 30.07 & 39.92 \\
\hline & SD & 38.22 & 39.57 & 21.35 & 22.09 & 18.05 & 14.73 & 0.25 & 0.24 & 15.58 & 22.43 \\
\hline
\end{tabular}

\section{Aerosol Optical Depth (AOD)}

Aerosol Optical Depths (AOD) which is a measure of the extinction of the sunbeam by atmospheric aerosols were analyzed over India to study the effects of the COVID-19 lockdown on aerosol concentration in the atmosphere. AOD data at $550 \mathrm{~nm}$ for $1^{0} \mathrm{spatial}$ resolution were extracted from the MODIS on-board Terra and Aqua satellites for the COVID-19 lockdown period (March 25 to May 31, 2020) and the same period of 2019. The mean AOD observed in 2020 was $0.35 \pm 0.13$, while over 2019 it was $0.39 \pm 0.16$. Compared to the same period in 2019, a 10.25\% reduction in the COVID-19 lockdown period was observed in India. IGP has always been the air pollution hotspot in India and reports high AOD levels. A clear decrease in the AOD values over IGP region can be seen in Fig 8. A significant decrease in AOD has been observed in southeast and northwest India. 


\section{International Journal of Current Science Research and Review}

ISSN: 2581-8341

Volume 04 Issue 10 October 2021

DOI: 10.47191/ijcsrr/V4-i10-16, Impact Factor: 5.825

IJCSRR@ 2021

www.ijjcsrr.org

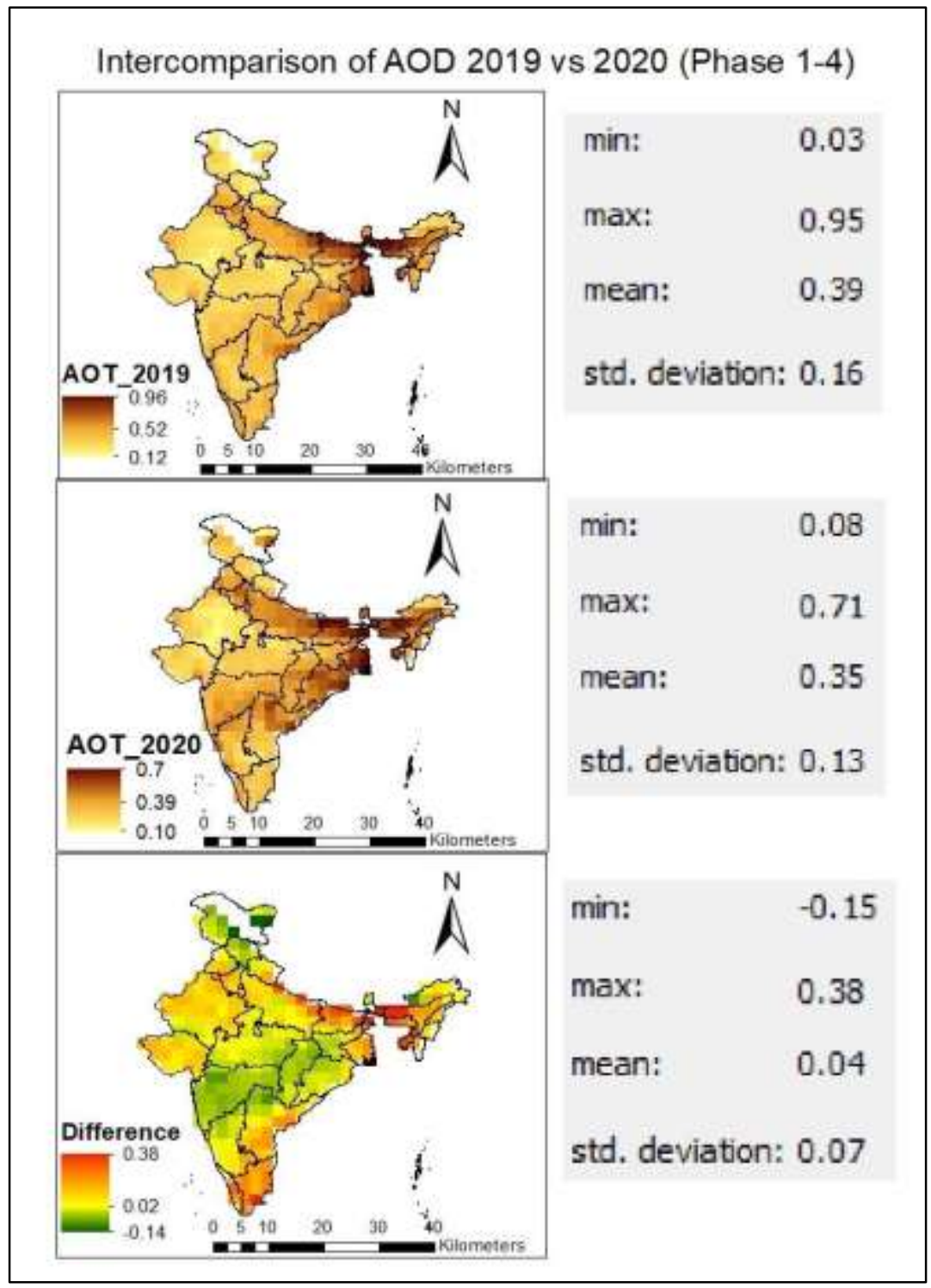

Fig.8. Variation of AOD concentration over India between $25^{\text {th }}$ march-31 ${ }^{\text {st }}$ May in 2019 and 2020.

\section{CONCLUSION}

COVID-19 has on the one hand affected the lives and income of many people and on the other hand has improved the quality of the environment. The lockdown in various states due to COVID-19 appears to show a significant improvement in air quality in India. The results of the study showed remarkable improvements in pollutant concentrations in all states. The particle concentration has decreased drastically in all states. $\mathrm{NO}_{2}$ and $\mathrm{CO}$ also showed reductions, but the reduction was not significant for every state. On the other hand, ozone showed a mixed response with increase and decrease, both of which were reported in different parts of India. A reduction in total AOD has been recorded across the country, which clearly demonstrates the positive effects of the lockdown on air pollution and can be viewed as a future mitigation strategy. These results will surely give the government some insight into the air quality for different states of India to help them decide on precautionary measures.

\section{ACKNOWLEDGEMENT}

The authors thank the Director General of Meteorology, IMD, Delhi for encouraging to carry out the study. 


\section{International Journal of Current Science Research and Review}

ISSN: 2581-8341

Volume 04 Issue 10 October 2021

DOI: 10.47191/ijesrr/V4-i10-16, Impact Factor: 5.825

IJCSRR@ 2021

www.ijesrr.org

\section{REFERENCES}

1. Bera B, Bhattacharjee S, Shit PK, Sengupta N, Saha S (2020) Significant impacts of COVID-19 lockdown on urban air pollution in Kolkata (India) and amelioration of environmental health. Environment, development and sustainability 1-28. https://doi.org/10.1007/s10668-02000898-5

2. Biswal A, Singh T, Singh V, Ravindra K, Mor S (2020) COVID-19 lockdown and its impact on tropospheric $\mathrm{NO}_{2}$ concentrations over India using satellite-based data. Heliyon, 6:e04764. https://doi.org/10.1016/j.heliyon.2020.e04764

3. Mahato S, Pal S, Ghosh K. G (2020) Effect of lockdown amid COVID-19 pandemic on air quality of the megacity Delhi, India. Science of the Total Environment 730:139086. https://doi.org/10.1016/j.scitotenv.2020.139086

4. Mor S, Kumar S, Singh T, Dogra S, Pandey V, Ravindra K (2020) Impact of COVID-19 lockdown on air quality in Chandigarh, India: understanding the emission sources during controlled anthropogenic activities. Chemosphere 263:127978. https://doi.org/10.1016/j.chemosphere.2020.127978

5. Shehzad K, Sarfraz M, Shah SGM (2020) The impact of COVID-19 as a necessary evil on air pollution in India during the lockdown. Environmental Pollution 266:115080. https://doi.org/10.1016/j.envpol.2020.115080

6. Singh RP, Chauhan A (2020) Impact of lockdown on air quality in India during COVID-19 pandemic. Air Quality, Atmosphere \& Health, 13: 921-928. https://doi.org/10.1007/s11869-02000863-1

7. Singh V, Singh S, Biswal A, Kesarkar AP, Mor S, \& Ravindra K (2020) Diurnal and temporal changes in air pollution during COVID-19 strict lockdown over different regions of India. Environmental Pollution, 266:115368.

https://doi.org/10.1016/j.envpol.2020.115368 covid19.apple.com/mobility

Cite this Article: Charu Tyagi, Vijay Kumar Soni, Ravi Ranjan Kumar, Arpit Tiwari (2021). Phase Wise Variation of Criteria Pollutants across India during COVID-19 Lockdown. International Journal of Current Science Research and Review, 4(10), 1337-1347 